\title{
Relationship between hypercholesterolemia and acute ischemic stroke among patients with type-2 diabetes: A case control study
}

\author{
Chaveepojnkamjorn $W^{1 *}$, Boonrasri $W^{2}$, Viwatwongkasem $C^{3}$, Siri $S^{4}$ and Kriengkaisakda $W^{5}$ \\ ${ }^{1}$ Department of Epidemiology, Faculty of Public Health, Mahidol University, Ratchathewi, Bangkok, Thailand \\ ${ }^{2}$ Bangpakong Health Office, Bangpakong District, Chachoengsao, Thailand \\ ${ }^{3}$ Department of Biostatistics, Faculty of Public Health, Mahidol University, Ratchathewi, Bangkok, Thailand \\ ${ }^{4}$ Department of Epidemiology, Faculty of Public Health, Mahidol University, Ratchathewi, Bangkok, Thailand \\ ${ }^{5}$ Bhuddasothorn Hospital, Muang District, Chachoengsao, Thailand
}

\begin{abstract}
Objectives: To identify the association of high blood cholesterol with the risk of acute ischemic stroke (AIS) among Thai patients with type-2 diabetes (PTDs).

Methods: A case control study was conducted among PTDs attending Bhuddasothorn Hospital in Chachoengsao, with 100 cases and 300 controls from $2013-2016$. Cases and controls were matched by sex, age ( \pm 5 years), residential area and attendance duration. Data were collected using questionnaires comprising two parts: demographic characteristics and medical data. Conditional logistic regression was applied to estimate the effect of high blood cholesterol on acute ischemic stroke among PTDs.

Results: Univariable conditional logistic regression showed risk factors for AIS among TPDs comprised history of atrial fibrillation, diastolic blood pressure, systolic blood pressure, HbA1c, history of CVD, FPG, total cholesterol, LDL cholesterol, creatinine, and microvascular complications ( $<<0.05$ ). For multivariable conditional logistic regression analysis, controlling for possible confounding factors revealed a total cholesterol level of 240-279 mg/dl and higher increased the risk of AIS by a factor of 4.3 and 7.7 times, respectively $(\mathrm{OR}=4.3,95 \% \mathrm{CI}=1.4-13.7 ; \mathrm{OR}=7.7,95 \% \mathrm{CI}=1.1-57.5)$.
\end{abstract}

Conclusion: A surveillance system of blood cholesterol among risk groups should be conducted in cooperation with information regarding cholesterol control and stroke prevention as an essential measure to reduce AIS risk.

\section{Introduction}

Cerebrovascular diseases (CVD) mainly include ischemic stroke and hemorrhagic stroke. At present, it has been well established that stroke is the second leading cause of death $[1,2]$. Its social burden increased from 38 to 61 million stroke cases between 1990 and 2020 [3]. The Global Burden of Diseases, Injuries, and Risk factors Study (GBD) reported approximately 16.9 million new stroke cases in 2010 [4]. Most comprised ischemic stroke (11.6 million cases) ending in 2.8 million deaths [4-7]. The GBD has predicted 12 million deaths and 200 million disability-adjusted life years (DALYS) lost to stroke in 2030 [4]. In Thailand, stroke is a major health burden and the leading cause of death and long term disability among the elderly [8]. According to epidemiology data from the Thai's Ministry of Public Health, over 50,000 stroke deaths occur annually, presenting an increasing trend of stroke death rate during the past 10 years, as shown in (Figure 1) $[9,10]$.

Similar to other parts of the world, ischemic stroke is the most common stroke type in the Thai population. Causes of ischemic stroke are likely to be multifactorial. Effects of hypercholesterolemia showed a higher risk of ischemic stroke, mainly in western countries [11-15]. In Thailand, quite a few studies have reported this association among patients with type- 2 diabetes. Therefore, the purpose of the study was to determine the association between high blood cholesterol and AIS occurrence among PTDs.

\section{Variable definitions}

Ischemic stroke is caused by a critical reduction of regional cerebral blood flow when the critical blood flow reduction lasts beyond a critical duration. One of the most widely used stroke schemes is the Trial of Org 10172 in Acute Stroke Treatment (TOAST) classification, which divides ischemic stroke in five categories: large artery atherosclerosis, cardiac embolism, small artery/lacunar occlusion, stroke of other determined etiology and stroke of undetermined etiology [16-19]. Ischemic stroke diagnosis is determined based on the code of I63, the International Classification of Diseases, 10th revision (ICD-10).

Hypercholesterolemia is a condition of high blood cholesterol. The National Heart, Lung and Blood Institute within the National Institutes of Health classifies total cholesterol of less than $200 \mathrm{mg} / \mathrm{dl}$ as desirable, $200-239 \mathrm{mg} / \mathrm{dl}$ as borderline high, and $\geq 240 \mathrm{mg} / \mathrm{dl}$ as high [20].

${ }^{\star}$ Correspondence to: $\mathrm{PH}$ Wisit Chaveepojnkamjorn, Department of Epidemiology, Faculty of Public Health, Mahidol University, Ratchathewi, Bangkok, 10400 Thailand, E-mail: wiziz.cha@mahidol.ac.th

Key words: hypercholesterolemia, acute ischemic stroke, patients with Type-2 diabetes

Received: July 30, 2018; Accepted: August 10, 2018; Published: August 17, 2018 


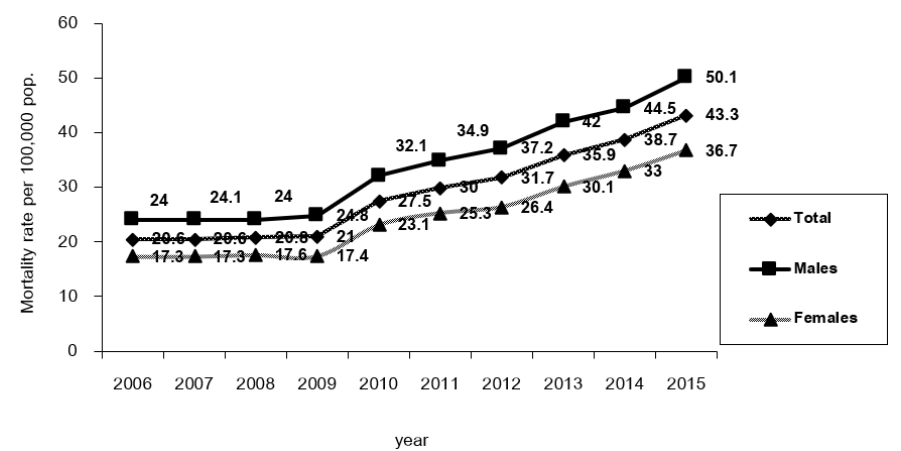

Figure 1. Mortality Rate of Stroke, Thailand, 2006-2015 Source: Bureau of Policy and Strategy, Ministry of Public Health [9,10]

\section{Methods}

\section{Study design, sample size and sampling technique}

A hospital-based matched case control study (1:3) was conducted at the Bhuddasothorn Hospital, Chachoengsao from 2013 to 2016 to identify the effect of blood cholesterol and AIS risk among PTDs. A total of 100 AIS cases and 300 controls were included in the study. The cases comprised PTDs newly diagnosed with AIS by neurologists and computer tomography scan. The controls comprised PTDs without AIS. Of the 400 participants, cases and controls were matched by age ( \pm 5 years), residential area and duration of attending. Both cases and controls used medical records comprising demographic factors, medical data and AIS status. The sample size was calculated using Stata 12 [21], where Po (0.04) and P1 (0.138) constituted the proportions of exposure in controls and cases, respectively [22]; $\mathrm{Z \alpha} / 2=1.96$ at $\alpha=0.05 ; \mathrm{Z} \beta=0.84$ at $\beta=0.20$. The calculated sample size was at least 91 among cases and 273 among controls. Subjects totalled 100 cases and 300 controls for the present study. The authors used the average medical data during the past three years for exposed factors.

\section{Ethics approval}

The study protocol was reviewed and approved by the Ethics Committee for Research in Human Subjects of the Faculty of Public Health, Mahidol University (171/2557), the Ethics Committee for Research in Human Subjects of the Chachoengsao Public Health Office (PH_CCO_REC 004/58) and the Ethics Committee for Research of Buddasothorn Hospital (BSH-IRB 005/2558). The information was collected using medical records. Confidentiality was maintained using an anonymous technique throughout the study to ensure privacy and the results were analysed as a whole group.

\section{Statistical analyses}

The data were analyzed using STATA (Release 12, StataCorp LP, College Station, TX, Serial number: 4012044037). Data were tabulated by means of descriptive statistics, univariable analyses and multivariable analyses. Categorical variables were given as frequency and percentage, crude odds ratio, $95 \%$ confidence interval (CI) of OR and p-value. The numerical variables were expressed as mean, minimum and maximum and standard deviation (SD). Univariable conditional logistic regression analysis was performed to differentiate proportional exposures between PTDs with AIS and controls for categorical variables. Adjusted odds ratio and the $95 \%$ CI of OR were calculated from multivariable conditional logistic regression to examine associations between high blood cholesterol and AIS occurrence, adjusted for potential confounding factors. A p-value of $<0.05$ was considered statistically significant in the analyses.

\section{Results \\ Demographic characteristics}

A total of 400 PTDs participated in the case control study. The average age of subjects was 67 years and (Table 1) outlines their demographic characteristics. To summarize, the majority were aged $\geq 70$ years $(43.0 \%, 43.3 \%)$, female $(68 \%)$, and duration of DM was 5 to 10 years $(68.0 \%, 63.7 \%)$. As shown in Table 1 , no significant difference was observed regarding demographics at baseline among PTDs ( $p$ $>0.05$ ) (Table 1).

\section{AIS and risk factors}

Using univariable conditional logistic regression, we found possible risk factors of AIS among PTDs included history of AF, diastolic BP, systolic BP, HbA1c, history of CVD, FPG, total cholesterol (TC), LDL cholesterol, creatinine and microvascular complications ( $p<0.05)$, as shown in (Table 2). Concerning multivariable conditional logistic regression analysis, TC showed association with AIS occurrence after controlling for possible confounding factors (history of AF, diastolic BP, systolic BP, HbA1c, history of CVD, FPG, creatinine and microvascular complications), (Table 3) and higher TC was significantly associated with increased risk of AIS. Risk of developing AIS with TC 240-279 $\mathrm{mg} / \mathrm{dl} 2$ and higher were 4.3 and 7.7 times, respectively, when compared with those of TC $<200 \mathrm{mg} / \mathrm{dl} 2(\mathrm{ORadj}=4.3,95 \% \mathrm{CI}=1.4-13.7$; ORadj= $7.7,95 \% \mathrm{CI}=1.1-57.5$ ), as shown in (Table 3 ).

\section{Discussion}

Study participants comprised PTDs attending Bhuddasothorn Hospital, Chachoengsao Province. Most comprised females (68\%) aged $\geq 70$ years (43\%). Results of multivariable analyses showed an association between TC and AIS among PTDs when controlling potential factors, which was consistent with related studies [23-25], while some studies found no association [26,27]. The present study showed $23 \%$ of TC $\geq 240 \mathrm{mg} / \mathrm{dl}$ among PTDs with AIS.

Hypercholesterolemia was able to cause stroke because continual high blood cholesterol would accumulate fatty plaque at the endothelial wall causing the endothelial wall to malfunction, and lose elasticity

Table 1. General characteristics of study subjects

\begin{tabular}{|c|c|c|c|c|c|}
\hline \multirow[t]{2}{*}{ Characteristics } & \multicolumn{2}{|c|}{$\begin{array}{c}\text { Cases } \\
(\mathrm{n}=100)\end{array}$} & \multicolumn{2}{|c|}{$\begin{array}{l}\text { Controls } \\
(\mathrm{n}=300)\end{array}$} & \multirow[t]{2}{*}{$\mathrm{p}$-value ${ }^{\mathrm{a}}$} \\
\hline & $\mathrm{n}$ & $\%$ & $\mathrm{n}$ & $\%$ & \\
\hline Age gr. (yrs) & & & & & 1.000 \\
\hline$<50$ & 7 & 7.0 & 21 & 7.0 & \\
\hline $50-59$ & 21 & 21.0 & 62 & 20.7 & \\
\hline $60-69$ & 29 & 29.0 & 87 & 29.0 & \\
\hline$\geq 70$ & 43 & 43.0 & 130 & 43.3 & \\
\hline Mean (SD) & \multicolumn{2}{|c|}{$66.9(11.1)$} & \multicolumn{2}{|c|}{$66.9(10.9)$} & \\
\hline Min-Max & \multicolumn{2}{|c|}{$42-90$} & \multicolumn{2}{|c|}{$43-89$} & \\
\hline Sex & & & & & 1.000 \\
\hline Male & 32 & 32.0 & 96 & 32.0 & \\
\hline Female & 68 & 68.0 & 204 & 68.0 & \\
\hline Duration of DM (yrs) & & & & & 0.584 \\
\hline$<5$ & 20 & 20.0 & 75 & 25.0 & \\
\hline $5-10$ & 68 & 68.0 & 191 & 63.7 & \\
\hline$>10$ & 12 & 12.0 & 34 & 11.3 & \\
\hline
\end{tabular}

${ }^{\mathrm{a}}$ chi-square test 
Table 2. Univariable conditional logistic regression analysis of factors associated with AIS among PTDs

\begin{tabular}{|c|c|c|c|c|c|c|c|}
\hline Characteristics & Cases & & Controls & & $\mathrm{OR}_{\mathrm{c}}$ & $95 \% \mathrm{CI}$ & p-value ${ }^{a}$ \\
\hline & n & $\%$ & n & $\%$ & & & \\
\hline \multicolumn{8}{|l|}{ History of AF } \\
\hline No & 94 & 94.0 & 299 & 99.7 & 1 & & \\
\hline Yes & 6 & 6.0 & 1 & 0.3 & 17.9 & $2.2-149.5$ & $0.001 *$ \\
\hline \multicolumn{8}{|l|}{ Diastolic BP (mmHg) } \\
\hline$<90$ & 87 & 87.0 & 293 & 97.7 & 1 & & \\
\hline$\geq 90$ & 13 & 13.0 & 7 & 2.3 & 7.1 & $2.5-20.1$ & $<0.001^{*}$ \\
\hline \multicolumn{8}{|l|}{ Systolic BP (mmHg) } \\
\hline$<140$ & 62 & 62.0 & 231 & 77.0 & 1 & & \\
\hline$\geq 140$ & 38 & 38.0 & 69 & 23.0 & 2.2 & $1.3-3.8$ & $0.003^{*}$ \\
\hline \multicolumn{8}{|l|}{ HbAlc (\%) } \\
\hline$<7$ & 15 & 15.0 & 139 & 46.3 & 1 & & \\
\hline $7-7.9$ & 15 & 15.0 & 65 & 21.7 & 2.2 & $1.0-4.9$ & $0.07^{*}$ \\
\hline $8-8.9$ & 85 & 26.0 & 48 & 16.0 & 5.6 & $2.6-12.0$ & $<0.001^{*}$ \\
\hline$\geq 9$ & 44 & 44.0 & 48 & 16.0 & 9.5 & $4.6-19.8$ & $<0.001 *$ \\
\hline \multicolumn{8}{|l|}{ History of CVD } \\
\hline No & 93 & 93.0 & 294 & 98.0 & 1 & & \\
\hline Yes & 7 & 7.0 & 137 & 2.0 & 3.5 & $1.2-10.4$ & $0.024 *$ \\
\hline \multicolumn{8}{|l|}{ FPG (mg/dl) } \\
\hline$<126$ & 22 & 22.0 & 127 & 42.3 & 1 & & \\
\hline$\geq 126$ & 78 & 78.0 & 173 & 57.7 & 3.4 & $1.9-6.3$ & $<0.001^{*}$ \\
\hline \multicolumn{8}{|l|}{ Total Cholesterol (mg/dl) } \\
\hline$<200$ & 70 & 70.0 & 233 & 77.7 & 1 & & \\
\hline $200-239$ & 7 & 7.0 & 53 & 17.7 & 0.4 & $0.2-1.0$ & 0.060 \\
\hline $240-279$ & 18 & 18.0 & 12 & 4.0 & 5.9 & $2.7-12.9$ & $<0.001 *$ \\
\hline$\geq 280$ & 5 & 5.0 & 2 & 0.6 & 8.2 & $1.5-43.7$ & $0.013 *$ \\
\hline \multicolumn{8}{|l|}{ LDL Cholesterol (mg/dl) } \\
\hline$<100$ & 42 & 42.0 & 126 & 42.0 & 1 & & \\
\hline $100-129$ & 23 & 32.0 & 105 & 35.0 & 0.7 & $0.4-1.2$ & 0.213 \\
\hline $130-159$ & 12 & 12.0 & 49 & 16.4 & 0.8 & $0.4-1.7$ & 0.531 \\
\hline $160-189$ & 17 & 17.0 & 16 & 5.3 & 3.1 & $1.4-6.8$ & $<0.006^{*}$ \\
\hline$\geq 190$ & 6 & 6.0 & 4 & 1.3 & 5.7 & $1.3-24.6$ & $0.020^{*}$ \\
\hline \multicolumn{8}{|l|}{ HDL Cholesterol (mg/dl) } \\
\hline$>60$ & 5 & 5.0 & 29 & 9.7 & 1 & & \\
\hline $41-59$ & 36 & 36.0 & 97 & 32.3 & 2.1 & $0.8-5.6$ & 0.159 \\
\hline$\leq 40$ & 59 & 59.0 & 174 & 58.0 & 1.9 & $0.7-5.2$ & 0.216 \\
\hline \multicolumn{8}{|l|}{ Triglyceride (mg/dl) } \\
\hline$<150$ & 52 & 52.0 & 187 & 62.3 & 1 & & \\
\hline $150-199$ & 26 & 26.0 & 58 & 19.3 & 1.6 & $0.9-2.9$ & 0.084 \\
\hline$\geq 200$ & 22 & 22.0 & 55 & 18.3 & 1.5 & $0.8-2.7$ & 0.196 \\
\hline \multicolumn{8}{|l|}{ Creatinine (mg/dl) } \\
\hline$\leq 1$ & 48 & 48.0 & 177 & 59.0 & 1 & & \\
\hline$>1$ & 52 & 52.0 & 123 & 41.0 & 1.7 & $1.0-2.8$ & $0.037 *$ \\
\hline \multicolumn{8}{|l|}{ Active smoking } \\
\hline No & 86 & 86.0 & 273 & 91.0 & 1 & & \\
\hline Yes & 14 & 14.0 & 27 & 9.0 & 1.9 & $0.9-4.5$ & 0.108 \\
\hline \multicolumn{8}{|l|}{ Alcohol consumption } \\
\hline No & 96 & 96.0 & 297 & 99.0 & 1 & & \\
\hline Yes & 4 & 4.0 & 3 & 1.0 & 4.0 & $0.9-17.9$ & 0.070 \\
\hline \multicolumn{8}{|l|}{ Microvascular complications } \\
\hline No & 64 & 64.0 & 212 & 70.7 & 1 & & \\
\hline 1 & 22 & 22.0 & 68 & 22.7 & 1.1 & $0.6-1.9$ & 0.741 \\
\hline$>1$ & 14 & 14.0 & 20 & 6.6 & 2.4 & $1.1-5.2$ & $0.024 *$ \\
\hline \multicolumn{8}{|l|}{ Body mass index $\left(\mathrm{kg} / \mathrm{m}^{2}\right)$} \\
\hline $18.5-22.9$ & 34 & 34.0 & 88 & 29.3 & 1 & & \\
\hline $23.0-24.9$ & 23 & 23.0 & 55 & 18.3 & 1.0 & $0.6-1.9$ & 0.903 \\
\hline $25.0-29.9$ & 29 & 34.2 & 107 & 35.7 & 0.7 & $0.4-1.2$ & 0.198 \\
\hline$\geq 30.0$ & 12 & 10.1 & 44 & 14.7 & 0.7 & $0.3-1.5$ & 0.316 \\
\hline
\end{tabular}




\begin{tabular}{|l|c|c|c|c|c|c|c|}
\hline & & & & & & \\
\hline & & & & & & \\
\hline
\end{tabular}

${ }^{a}$ Univariable conditional logistic regression analysis performed on 100 matched pairs, $\mathrm{AIS}=\mathrm{Acute}$ ischemic stroke, $\mathrm{AF}=\mathrm{atrial}$ fibrillation, $\mathrm{BP}=\mathrm{blood}$ pressure, $\mathrm{HbA} \mathrm{c}=$ hemoglobin $\mathrm{A} 1 \mathrm{c}$ $\mathrm{CVD}=$ cardiovascular diseases, $\mathrm{FPG}=$ fasting plasma glucose, $\mathrm{OR}_{\mathrm{c}}=$ crude odds ratio, $\mathrm{CI}=$ confidence interval

*Significant at p-value $<0.05$

Table 3. Multivariable conditional logistic regression analysis of cholesterol associated with AIS patients

\begin{tabular}{|c|c|c|c|c|c|c|}
\hline Variables & $\mathrm{OR}_{\mathrm{c}}$ & $95 \% \mathrm{CI}$ & p-value & $\mathbf{O R}_{\text {adj }}$ & $95 \% \mathrm{CI}$ & p-value \\
\hline \multicolumn{7}{|c|}{ Total Cholesterol (mg/dl) } \\
\hline$<200$ & 1 & & & 1 & & \\
\hline $200-239$ & 0.4 & $0.2-1.0$ & 0.058 & 0.8 & $0.4-1.7$ & 0.069 \\
\hline $240-279$ & 5.4 & $2.3-12.9$ & $<0.001$ & 4.3 & $1.4-13.7$ & $0.013 *$ \\
\hline$\geq 280$ & 8.2 & $4.6-19.8$ & 0.013 & 7.7 & $1.1-57.5$ & $0.045^{*}$ \\
\hline \multicolumn{7}{|c|}{ LDL Cholesterol (mg/dl) } \\
\hline$<100$ & 1 & & & 1 & & \\
\hline $100-129$ & 0.7 & $0.4-1.2$ & 0.213 & 0.7 & $0.4-1.5$ & 0.409 \\
\hline $130-159$ & 0.8 & $2.3-12.9$ & 0.531 & 0.5 & $0.2-1.3$ & 0.153 \\
\hline $160-189$ & 3.1 & $2.3-12.9$ & 0.006 & 2.6 & $0.9-6.7$ & 0.055 \\
\hline$\geq 190$ & 5.7 & $4.6-19.8$ & 0.020 & 5.0 & $0.7-33.8$ & 0.097 \\
\hline
\end{tabular}

$\mathrm{OR}_{\mathrm{c}}=$ crude odds ratio, $\mathrm{AIS}=$ acute ischemic stroke, $\mathrm{CI}=$ confidence interval

$\mathrm{OR}_{\mathrm{adj}}^{\mathrm{c}}=$ adjusted odds ratio for history of AF, diastolic BP, systolic BP, HbA1c, history of CVD, FPG, creatinine, and microvascular complications

*Significant at $\mathrm{p}$-value $<0.05$

leading to atherosclerosis $[28,29]$. Accumulated plaque would cause endothelial stenosis and occlusion, and reduce cerebral blood flow (CBF). When CBF is insufficient for the brain tissue, the brain cells would die and cause the ischemic stroke.

Additionally, ischemic stroke might be a result of acute cerebral stenosis. After atherosclerosis, endothelial inflammation would inevitably appear, and causing a fracture in the fatty plaque, activating the accumulation of blood platelets followed by acute stenosis $[28,29]$ and acute ischemic stroke [30,31].

Primary prevention involves appropriate dietary control, for example, using the dietary approach to stop hypertension [32,33], e.g., maintaining a cereal, vegetables, fruit and low fat diet. PTDs constitute a risk group for stroke $[14,34]$. Therefore, glycemic control at normal level should be practiced continually to help reduce AIS risk. Currently, the American Heart Association and the American Stroke Association recommend that the ideal glucose level after AIS is between 140 to $180 \mathrm{mg} / \mathrm{dl}$ [34]. In addition, PTDs mostly present hypertension [35]. Therefore, hypertension control constitutes a crucial factor in reducing stroke risk [36,37]. At present, many tools are available to evaluate stroke, namely, the Stroke Risk Calculator, Stroke Risk Quiz of the American Heart Association/American Stroke Association, the National Institute of Health Stroke Scale (NIHSS) Neurologic Examination, ABCD2 score and others. For Thais aged 35 to 70 years, the Thai CV risk score was made to evaluate stroke.

In summary, a surveillance system of blood cholesterol among risk groups should be conducted along with providing knowledge of stroke and self-care prevention, implementing health promoting campaigns including proper regular exercise, healthy diet, weight control, risk avoidance such as smoking and alcohol consumption, and basic techniques for maintaining a healthy lifestyle among risk groups, as they will help extensively reduce risk of developing stroke [38-40].

\section{Advantages and limitations of the study}

This case control study had some advantages. First, Buddasothorn Hospital is the tertiary care centre for the east part of Thailand. Second, the subjects were easily identified and provided sufficient numbers.
Finally, cases were reduced classification bias. Some limitations of this study should be noted. First, the study was a hospital based matched case-control study; therefore, the representative target population couldn't be mentioned. Second, selecting suitable controls was difficult. However, we matched cases and controls by age, residence and duration of attending.

\section{Acknowledgement}

The authors acknowledge the participants and staff of the Bhuddasothorn Hospital for their cooperation and participation in the study, and also wish to extend our deep appreciation to those unmentioned here for their kindness and encouragement.

\section{Sources of funding}

This study was supported for publication by a grant of the China Medical Board (CMB) Faculty of Public Health, Mahidol University, Bangkok, Thailand.

\section{Conflict of interest}

The authors have no conflicts of interest associated with the material presented in this paper.

\section{References}

1. Strong K, Mathers C, Bonita R (2007) Preventing stroke: saving lives around the world Lancet Neurol 6: 182-187. [Crossref]

2. Johnston SC, Mendis S, Mathers CD (2009) Global variation in stroke burden and mortality: estimates from monitoring, surveillance, and modelling. Lancet Neurol 8: 345-354. [Crossref]

3. Mackay J, Mensah GA (2004) The atlas of heart disease and stroke. Geneva: World health organization.

4. Feigin VL, Krishnamurthi R (2016) Epidemiology and risk factors: global burden of stroke. In: Grotta JC, Albers GW, Broderick JP, et al, eds. Stroke: pathophysiology, diagnosis and management. 6th ed. China: Elsevier pp: 165-206.

5. Murray CJ, Ezzati M, Flaxman AD, Lim S, Lozano R, et al. (2012) GBD 2010: design, definitions, and metrics. Lancet 380: 2063-2066. [Crossref]

6. Global Burden of Disease Stroke Expert Group, Bennett DA (2012) Methodology of the global and regional burden of stroke study. Neuroepidemiology 38: 30-40. [Crossref] 
7. Feigin VL, Forouzanfar MH, Krishnamurthi R, Mensah GA, Connor M, et al. (2014) Global and regional burden of stroke during 1990-2010: findings from the Global burden of disease study 2010. Lancet 383: 245-254. [Crossref]

8. Bureau of policy and strategies (2016) Ministry of public health. Thailand health profile 2011-2015. Bangkok: The war veterans organization of Thailand.

9. Bureau of policy and strategies (2010) Ministry of public health. Public health statistics 2010. Bangkok: The war veterans organization of Thailand.

10. Bureau of policy and strategies (2016) Ministry of public health. Public health statistics 2015. Bangkok: The war veterans organization of Thailand.

11. Suwanwela NC (2014) Stroke epidemiology in Thailand. J Stroke 16: 1-7. [Crossref]

12. Nilanont Y, Nidhinandana S, Suwanwela NC, Hanchaiphiboolkul S, Pimpak T, et al. (2014) Quality of acute ischemic stroke care in Thailand: a prospective multicenter country wide cohort study. J Stroke Cerebrovasc Dis 23: 213-219.

13. Hanchaiphiboolkul S, Puthkhao P, Towanabut S, Tantirittisak T, Wangphonphatthanasiri $\mathrm{K}$, et al. (2014) Factors predicting high estimated 10-year stroke risk: Thai epidemiology stroke study. J Stroke Cerebrovasc Dis 23: 1969-1974. [Crossref]

14. Dhamasaroja P (2008) Baseline characteristics of patients with acute ischemic stroke in suburban area of Thailand. J Stroke Cerebrovasc Dis 17: 82-85. [Crossref]

15. Hanchaiphiboolkul S, Poungvarin N, Nidhinandana S, Suwanwela NC, Puthkhao P, et al. (2011) Prevalence of stroke and stroke risk factors in Thailand: Thai Epidemiologic Stroke (TES) Study. J Med Assoc Thai 94: 427-436. [Crossref]

16. Grotta JC, Albers GW, Broderick JP, Kasner SE (2016) Stroke: pathology, diagnosis, and management. 6th ed. China: Elsevier.

17. Adams HP, Bendixen BH, Kappelle LJ, Biller J, Love BB, et al. (1993) Classification of subtype of acute ischemic stroke. Definitions for use in a multicenter clinical trial. Stroke 24: 35-41. [Crossref]

18. Furie KL, Lev MH, Koroshetz WJ (2007) Evaluation of acute stroke etiologies. In Greer DM, editor. Acute ischemic stroke: an evidence-based approach. New Jersey: John Wiley \& Sons pp: 197-212.

19. Ay H (2016) Classification of ischemic stroke. In: Grotta JC, Albers GW, Broderick JP, Kasner SE, Lo EH, et al. (editors.) Stroke: pathology, diagnosis, and management. 6th ed. China: Elsevier pp: 295-307.

20. National Cholesterol Education Program (Accessed 29 January 2018, at https://www. nhlbi.nih.gov/files/docs/guidelines/atglance.pdf).

21. Dupont WD (1988) Power calculations for matched case-control studies. Biometrics 44: 1157-1168. [Crossref]

22. Sacco RL, Shi T, Zamanillo MC, Kargman DE (1994) Predictors of mortality and recurrence after hospitalized cerebral infarction in an urban community: the Northern manhattan stroke study. Neurology 44: 626-634.

23. Iso H, Jacobs DR Jr, Wentworth D, Neaton JD, Cohen JD (1989) Serum cholestero levels and six-year mortality from stroke in 350,977 men screened for the multiple risk factor intervention trial. $N$ Engl J Med 320: 904-910.

24. Benfante R, Yano K, Hwang LJ, Curb JD, Kaqan A, et al. (1994) Elevated serum cholesterol is a risk factor for both coronary heart disease and thromboembolic stroke in hawaiian japanese men. Implications of shared risk. Stroke 25: 814-820. [Crossref]

25. Lewington S, Whitlock G, Clarke R, Sherliker P, Emberson J, et al. (2007) Blood cholesterol and vascular mortality by age, sex, and blood pressure: a meta-analysis of individual data from 61 prospective studies with 55,000 vascular deaths. Lancet 370: 1829-1839. [Crossref]
26. Sharhar E, Chambless LE, Rosamond WD, Boland LL, Ballantyne CM, et al (2003) Plasma lipid profile and incident ischemic stroke: the atherosclerosis risk in communities (ARIC) study. Stroke 34: 623-631. [Crossref]

27. Anonymous (1995) Cholesterol, diastolic blood pressure and stroke: 13,000 strokes in 450,000 people in 45 prospective cohorts. Prospective studies collaboration. Lancet 346: $1647-1653$.

28. Ito MK (2010) Dyslipidemia. In Chishalm-Buens M, Schwinghammer T, Wells B Malone P, Kolesar J, Dipiro J, editors pharmacotherapy principles \& practice. 2nd ed., Philadelphia: McGraw-Hill; pp: 229-248.

29. Tabert RL (2011) Dyslipidemia. In Dipiro JT, Talbert RL, Yee GC, Matzke GR, Wells BG, Posey LM. Pharmacotherapy a pathophysiologic approach. 8th ed., Philadelphia: McGrawHill. pp: 365-388.

30. Faxon DP, Fuster V, Libby P, Beckman JA, Hiatt WR, et al. (2004) Atherosclerotic vascular disease conference: writing group III: pathophysiology. Circulation 109: 2617-2625. [Crossref]

31. Powers WJ (2016) Cerebral blood flow and metabolism: regulation and pathophysiology in cerebrovascular disease. In Grotta JC, Albers GW, Broderick JP, Kasner SE, Lo EH, Mendelow AD, Sacco RL, Wong LKS, editors. Stroke: pathology, diagnosis, and management. 6th ed. China: Elsevier. p. 28-46.

32. Bazzano LA, Green T, Harrison TN, Reynolds K (2013) Dietary approaches to prevent hypertension. Curr Hypertens Rep 15: 694-702. [Crossref]

33. Sacks FM, Svetkey LP, Vollmer WM, Appel LJ, Bray GA, et al. (2001) Effects on blood pressure reduced dietary sodium and the Dietary Approaches to Stop Hypertension (DASH) diet. DASH-Sodium collaborative research group. $N$ Engl J Med 344: 3-10. [Crossref]

34. Shah SMA, Shah SM, Khan S, Rehman S, Khan Z, et al. (2013) Addressing the impact of stroke risk in a case control study in tertiary care hospitals: a case-control study in tertiary care hospitals of Peshawar, Khyber Phukhtoonkhwa (KPK) Pakistan. BMC Res Notes 6: 268. [Crossref]

35. Seshadri S, Wolf PA (2016) Modifiable risk factors and determinants of stroke. In Grotta JC, Albers GW, Broderick JP, Kasner SE, Lo EH, Mendelow AD, Sacco RL, Wong LKS, editors. Stroke: pathology, diagnosis, and management. 6th ed. China: Elsevier. pp: 217-233.

36. (1998) UK Prospective Diabetes Study Group. Tight blood pressure control and risk of macrovascular complications in type 2 diabetes: UKPDS 33. BMJ 317: 703-713.

37. Meschia JF, Bushnell C, Boden-Albala B, Braun LT, Bravata DM, et al. (2014) Guidelines for the primary prevention of stroke: a statement for healthcare professionals from the American heart association/american stroke association. Stroke 45: 3754 3832. [Crossref]

38. Chiuve SE, Rexrode KM, Spiegelman D, Logroscino G, Manson JE, et al. (2008) Primary prevention of stroke by healthy lifestyle. Circulation 118: 947-954. [Crossref]

39. Brainin M, Teuschl Y, Matz K (2010) Common risk factors and prevention. In: Brainin M, Heiss WD, editors. Textbook of stroke medicine. 1st ed. New York: Cambridge University Press. pp: 89-104.

40. Goldstein LB, Sacco RL (2016) Preventing a first stroke. In Grotta JC, Albers GW, Broderick JP, Kasner SE, Lo EH, Mendelow AD, Sacco RL, Wong LKS, editors. Stroke: pathology, diagnosis, and management. 6th ed. China: Elsevier. pp: 280291.

Copyright: $(02018$ Chaveepojnkamjorn W. This is an open-access article distributed under the terms of the Creative Commons Attribution License, which permits unrestricted use, distribution, and reproduction in any medium, provided the original author and source are credited. 